\title{
Comparative Analysis of Flooding in Mandra, Athens 2017 and Western Attica, Athens 1961: Actions, Response and Human Resources
}

\author{
Zacheilas Christos \\ PhD Candidate, Department of Social Sciences, \\ University of Crete, Crete, Greece
}

\begin{abstract}
On November 15, 2017 a flash flood struck West Attica with intense effects in Mandra and other cities, leading to many people going missing and causing the death of many people as well as material damages. Another storm took place during November 1961 with 40 victims and countless material damages as well. This study investigates the flooding problems and its consequences in Mandra (2017) and Western Attica (1961) and whether the Greek State is working in a direction of resilience and sustainability to avoid substantial damage in the future. Civil Protection, education and flood risk management play a lifesaving and life-sustaining role in an emergency situation and are the mechanisms that are crucial in order to prevent and mitigate damage.
\end{abstract}

Keywords: Human Resources, Floods, Response, Civil Protection, Preparedness

\section{INTRODUCTION}

Floods are one of the most powerful phenomena on earth, causing enormous damage all over the world. Statistics show that floods have quite a large impact on human well-being and economy. Economic damage, eco-system damage and historical and cultural values damage constitute direct consequences of flood. They lead to the loss of human life and cause human health effects [Hajat et al., 2005; WHO, 2002] [1,2]. Previous studies focusing on floods and its impact includes, among others, Coates (1999) about the situation in Australia, Mooney and French (1983) about United States and Sörensen and Rana (2013) about Sweden and India $[3,4,5]$. Although every flood can be considered as a unique event with unique characteristics, patterns may be observed when a large number of floods are studied e.g. floods from rivers, precipitation, tides, etc.

A natural flood can be either slow in development or fall into the category of the flash flood, which, in Greece, is the most common type of flooding. In Greece, most floods occur due to torrential rains, which accompany the periods of recession. The flash flood is the result of atmospheric disturbances, accompanied by precipitation, with large amounts of rain in a short period of time. Flash floods are caused by storms that move slowly or move over the same area. In the tropics, they are also caused by hurricanes or tropical cyclones. Many factors contribute in a flash flood, such as: rainfall intensity and duration, topography, soil conditions, plant coverage, deforestation and urbanization. Flash floods occur in a short time of a few hours or less and result in a rapid rise of the water level, which can subsequently cause major disasters in constructions such as buildings and bridges but also to drift cars, uproot trees, etc. Floods caused by heavy rainfall can cause devastating landslides (mud slides). Most flood victims are a result of flash floods. 
The Attica water basin, and in particular the sub-basin of the mainland, plays a very important role in the economic life of the country, since more than $30 \%$ of its population resides, works and acts in it. Due to its terrain, the rainwater systems coming from the south and southwest are raised to the hillsides of the basin and the surrounding mountain formations and are liquefied. As a result, the area is occasionally characterized by intense sudden rainfall that puts the carrying capacity of the hydrographic network to the test and often results in floods. These intense rainfalls suddenly charge the hydrographic network with rainwater as well as with alluvial sludge derived from the erosion of the mountainous areas and deposited in the plains, which are often the cause of changes in the morphology of the hydrographic network, the reduction of its capacity to discharge which subsequently leads to overflows and ultimately floods. Finally, human activity and urbanization also catalyze the occurrence of ever-increasing flood phenomena as they reduce waterlogging and pooling time. One of the main problems is that although these phenomena occur quite frequently there are no policies and practices in place that can help the population deal with the problem and authorities to provide support in a most effective way.

This study investigates the flooding problems and its consequences in Mandra (2017) and Western Attica (1961) in which 23 and 40 persons were killed respectively. Western Attica and the specific flood of 2017 in the area of Mandra have been chosen because they both belong to the broader area of Attica, sharing the same characteristics in terms of climate, geology and civil protection mechanisms. Due to the same main characteristic features of flooding in the area and the time gap between the two events, the comparison provides an excellent opportunity to analyse the actions taken, the responses given and the management of human resources within a period of approximately 50 years. The objectives of the study includes an overview of the flooding situation and problems that arose in both cases, the consequences of the flooding and the damage caused by it to the population but also to infrastructure and finally an assessment of whether the Greek State is working in a direction of resilience and sustainability to avoid substantial damage in the future.

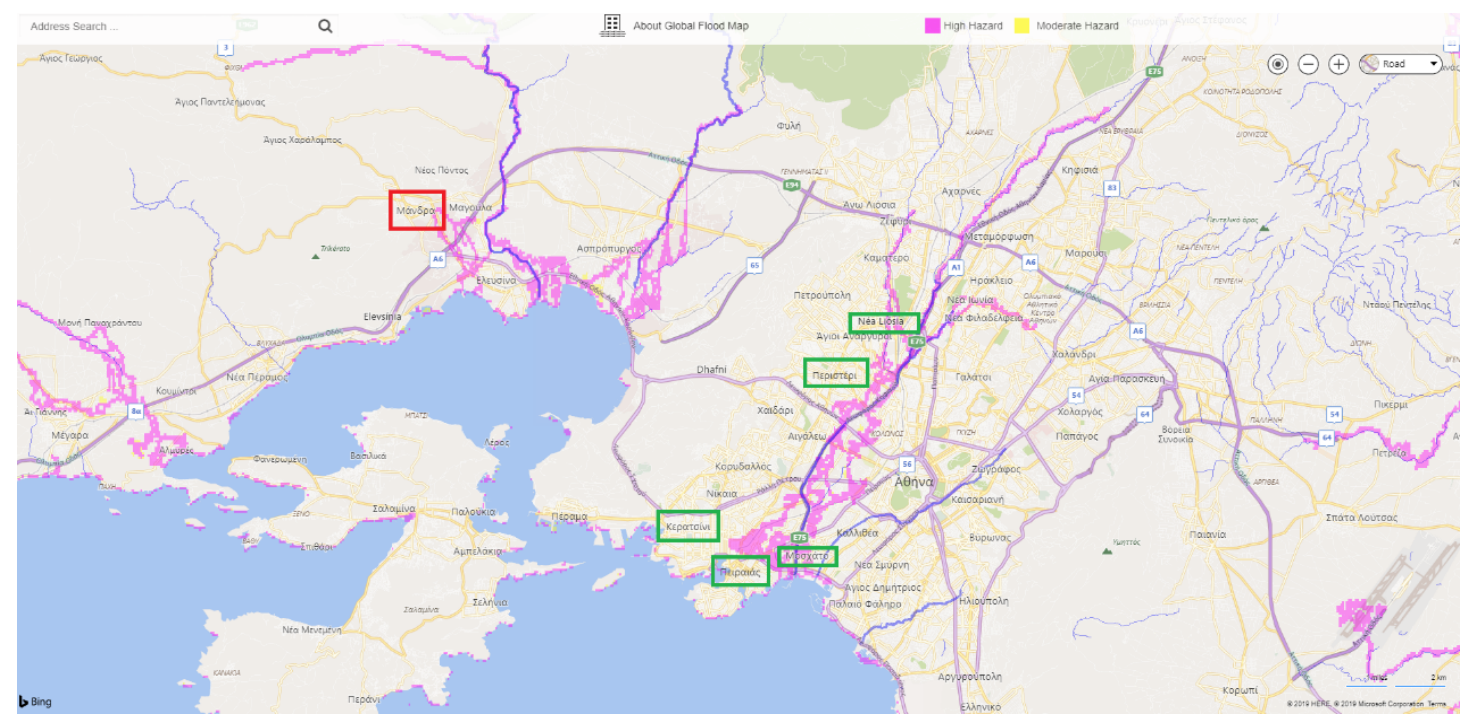

Figure 1 Map of Attica, indicating the affected areas (Mandra 2017 - red) (W.Attica 1961 green), with flood hazards highlighted in pink and rivers drawn with blue colour (source: fmglobal.com)

\section{STUDY AREA - MANDRA}

The Municipality of Mandra is the most extensive municipality of Western Attica (206,000 acres) and one of the largest in Greece. It is located between Elefsina, Megara, Vilia, Erythres and Oinoi with direct access from the old national road of Athens - Thiva. Mandra has an 
altitude of 84 meters from the sea surface, at latitude 38.0718486842 and longitude 23.4939783987.

In the early hours of November 15, 2017, after a heavy rainfall, a flash flood struck West Attica with intense effects in Mandra, Nea Peramos, Magoula and Elefsina, leading to many people going missing and finally resulting in causing the death of many people as well as huge material damages. The flood was deemed the third largest in the history of Attica according to the number of casualties. By November 19th, the number of deaths had already been increased, reaching 20. Within a four hour period, the main bulk of water fell to Mount Pateras and due to the rainfall of the previous two days, the already saturated soil was unable to absorb the amount of water that "descended" from the mountain.

The calculation of the rainfall by IMERG (Integrated Multi-satellite Retrievals for GPM), based on the initiative of NASA to measure the world precipitation phenomena (NASA Global Precipitation Measurement), lead to a detailed all space-time features recording of the storm which testifies to the extremity of the event. According to these initial estimates, the upstream of Mandra received $\sim 150 \mathrm{~mm}$ rainfall in about 7 hours (from 00: 30-07: 30 UTC on November 15,2017 ), corresponding to about $40 \%$ of the annual rainfall in the region. [Lekkas et al., 2017] [6].

The phenomenon that caused the national tragedy was local and had the characteristics of a tropical storm. Similar floods had taken place in the suburbs of Western Attica in November 1961 and 1977 after heavy rainfall.

In the days that followed and due to the size and extent of the destruction, there were political reactions where those responsible for the disaster were sought. Of course, there was also a major aid effort to the affected areas by citizens as well as the government. On the same day of the disaster, Prime Minister Alexis Tsipras declared the day as national mourning day for the victims, and the following day he visited the affected area for inspection. The most affected areas were Mandra and Nea Peramos. Eventually, the amount of victims reached 23, by the 30th November 2017. The autopsy in the area of Mandra identified 1064 building disasters, of which 794 were residences, 126 were business premises, 8 were public buildings, and the remaining 136 were warehouses and basements. In the area of Megara and Nea Peramos, the autopsy showed 448 buildings, with 228 houses, 38 business premises, 6 public buildings and the remaining 123, warehouses and basements. The size of the destructions and the number of dead further supports the argument raised in mass media that the preventive mechanism didn't address adequately the problem and it was obvious that the population was not aware of the concrete steps that should be followed.

\section{POST-FLOOD ACTIONS AND CIVIL PROTECTION}

Civil protection in Greece is organised as a co-ordinated resource system whereby national, regional, provincial and local authorities work together with local and public institutions and services. Each of these authorities and institutions has developed its own part of the national civil protection plan (Xenokrates) and makes its own contribution towards achieving the aims of civil protection.

Regarding post flood actions, many actors were involved, in order to mitigate the damage and offer help to those affected by the flood (such as the General Secretariat for Civil Protection). Clothing, food and shelter was offered to the population by nearby municipalities, charity works and even external aid from Cyprus. However, many were the actors that were responsible for not handling the situation correctly and not having already worked on issues 
that were crucial in order to prevent the disaster. Among these actors were the Directorate of Flood Protection (DFP) of the Region of Attica and the Department of Technical Works (DTW). Information is provided by the General Inspector of Public Administration of the Hellenic Republic, via the translated Audit report concerning the flooding (2018) [7].

\section{General Secretariat for Civil Protection (GSCP)}

The General Secretariat for Civil Protection (GSCP) is a subdivision of the Ministry of the Interior and was established pursuant to Article 4 paragraph 1 of the Law 2344/1995 (Greek Government Gazette A' 212). The GSCP's mission is to design, plan, organize and coordinate actions regarding risk assessment, prevention, preparedness, information and response to natural, technological or other disasters or emergencies, to coordinate rehabilitation operation, to monitor the above actions and to inform the public on these issues. Moreover, it organizes and supervises the Civil Protection Volunteerism System. In the context of this mission, the Hellenic Fire Service is a subdivision and operational arm of the GSCP. At the national level, the Civil Protection Operations Centre coordinates and manages the provision of resources to address emergencies, in order to strengthen the bodies operating in the field of short-term consequence management. The CPOC operates throughout the year, on a 24-hour basis, is staffed by officers and non-commissioned officers of the Armed Forces, the Hellenic Police, the Hellenic Coast Guard and the Hellenic Fire Service and in case of an emergency is supported by specialized scientific staff, if necessary.

The General Secretariat for Civil Protection with document no. 27694 / 20-2-2018 informed the Ministry of Administrative Reconstruction of its instant actions, immediately after the event of 15-11-2017, while also declaring the areas of the Municipal Unit of Nea Peramos of the Municipality of Megareon, the Municipal Unity of Magoula of the Municipality of Elefsina and of the Municipal Unity of Mandra of the Municipality of Mandra - Idylia (Regional Unity of Western Attica of the Region of Attica) in a state of emergency Civil Protection, for six months, until 15-5-2018.

The Secretariat undertook the coordination of the work of allocating the additional (of the Region's own resources) of resources and means hired from 15-11-2017 to 22-12-2017. On a daily basis, there was a large number (more than 60) of machines, vehicles and their staff (project machines, pumps, trucks, tank trucks, transport vehicles, platforms, cranes, etc.) aiming to mitigate the risks and rehabilitate the daily operations of affected areas. For this purpose, settlement 235815 / 15-11-2017 of the Regional Governor of Attica (IDA: 72HX7L7A60) was issued, concerning the allocation of an amount of up to three million euros (3.000.000 €) for the rental of machinery, vehicles and their necessary personnel. It was approved with the no. 3171/17 (ID: 6Z457L7-7LX) decision of the Economic Committee of the Region of Attica.

With the assistance of the above-mentioned instruments (as well as other means provided by the Technical Services of the Region, the affected Municipalities, EYDAP (Athens Water Supply and Sewerage Company) and private individuals), huge quantities of dirt and other materials from various places were removed under the responsibility of the stakeholders and services, thus cleaning the affected areas. Vehicles that had been swept away by rainfall at the old national road of Athens-Thebes were also removed and were temporarily transferred to former Army Camp 305 in Mandra to be picked up by their owners. Debris and other materials collected from the affected areas were transferred to an inactive quarry of TITAN SA (a cement and building materials production company) in the Municipality of Mandra - Idylia. 


\section{Directorate of Flood Protection (DFP) (Region of Attica)}

The Department of Flood Protection of the Region of Attica has the mission to design, plan, coordinate, as well as study, execute, supervise and receive storm grids, delimit - settle watercourses and handle all flood defense projects in cooperation with the Municipalities and the Ministry of Transport and Networks in accordance with the legislation in force. It was one of the actors that due to the lack of a strategic contingency plan and the bureaucracy that characterizes the approval of its actions lead to unnecessary confusion and delay of response to the disaster. More specifically:

In the context of the examination of the relevant issue, the Egaleo Forestry Office with its no. 1026 / 8-8-2014 document, requested additional copies of the Topographic Diagram, which were submitted under document no. 25572 / 18-9-2014 of the above Directorate and the issuance of the relevant act was expected.

The main request of the DFP concerned the issuance of a designation act for the study of a public flood defense project, for which it is mandatory under law, for all the pre-auction approvals to be completed, "in order for the construction to begin without delay and run uneventfully". Nevertheless, the request remained pending (until 20-2-2017, the date when the Forestry Authority informed the DPF of the posting of the forest maps) even though it had to be handled with absolute priority by the Forestry Office according to what the Directorate mentioned.

On the aforementioned date, with letter No 15330/978 / 20-02-2017, the Forestry Authority of Egaleo commented on the subject: "Notification for the suspension of forest maps - pending application", replied to the DPF regarding the pending application that: "Following the posting of the forestry maps the procedure provided for in Article 14 of Law 998/79 is terminated and the application is therefore closed". The aforementioned letter from the Forestry Authority of Egaleo overturned the timetable, as the procedure for the designation of the land had to start again from the beginning, according to the DPF.

On 12-09-2017 with its document No. 461087/1954 the Forestry Authority of Egaleo informed the DPF that the Results of Environmental Inspections Department (REID) is also an authorization that deals with immediate interventions in forest areas that are in need of assistance and that the procedure is to firstly investigate the nature (forest or not) of the land that the task is going to be executed in (paragraph 1 of article 5 of Law 4467/2017). It then informed that the Forestry Department or the Forestry Mapping Department should issue a certificate of the nature of the land in order for them to proceed.

Finally, the DPF (Region of Attica) committed that after the auction of the project and before the start of the task, the Forestry Department will apply for the relevant installation permit, so that the works can be started immediately.

\section{Department of Technical Works (DTW) (Region of Attica)}

The Department of Technical Works of the Region of Attica was also one of the actors that had to confront its own bureaucratic issues.

In 2015, the Department of Road Construction was commissioned by the Region of Attica, a study for a road modification of a road of approximately $10 \mathrm{~km}$ length (from the position of Km 0,00 to $\mathrm{Km} 9+584,05$ ), which concerned the updating of an existing study that was found in the archive of the abolished Directorate of Regulations and Control of Organizations (former Ministry of Infrastructure, Transport and Networks), with the application of the new regulations, while taking into account the final hydraulic study of the sewerage and drainage of the road. 
Subsequently, a study was submitted at the Directorate of Decentralized Management of Attica regarding the renewal and modification of the Environmental Terms (Protocol No. 192428 / 710-2015). The approval of said document was still pending, because the requisite qualification act had not yet been issued by the competent Forestry Authority.

Following the catastrophic floods, and given that the Sures stream ("Skylorema" in the Old National Road Elefsina - Thiva section) has been identified as of particular environmental interest and knowing the time-consuming bureaucratic procedures for demarcation and approval of its restoration projects, while also taking into account the need for immediate restoration of the road network after the floods, it was proposed by the DTW to replace the route with a new one.

Thus, the need for an extensive research object arose, on the one hand, by the modification of the designation of ONRET (Old National Road of Elefsina-Thiva) by Km $5+500$ to approx. Km 8 +500 and on the other hand by updating the study between the $\mathrm{Km} 9+854.05$ and $\mathrm{Km} 17+$ 727.

It is noted that on 5-3-2018 the decision approving environmental terms was published entitled "Renewal - Modification" nr.141011- 12.10.2005 Joint Ministerial Decision, approving the improvement and widening of the Mandra-Reds section of the Old National Road of Athens - Thiva, in the Prefecture of Western Attica.

\section{CONCLUSIVE FACTORS FOR MANDRA}

Critical factors that have contributed to the immense destruction caused by the flood are the arbitrary human interventions within the river bed, the inadequacy of existing technical works (either due to construction or non-cleaning / maintenance) or the complete absence of flood protection and drainage measures in some areas, and partly the landscape changes due to some small burned areas upstream, but mainly due to urban extensions where the construction of buildings blocks the flow of streams. Subsequently, the lack of any central strategic planning, mitigating plans and any type of awareness raising campaign provided to locals was also evident. [Kontoes et al., 2018] [8].

Indicatively, the following examples are illustrated:

1) The urban area of Mandra is built within the natural flow of the St Catherine / Katsimidis stream without any settlement of the bed or any flood defenses in this area (eg deflection)

2) The natural flow of the Soures stream is blocked in various places by private and also municipal facilities (construction site of the Municipality of Mandra),

3) There are asphalted roads to the west and to the north of the urban area of Mandra, which cross the streams without any bed arrangement or technical work (e.g manhole, bridge)

4) The unassigned Loutsa stream continues as a road under the Attiki Odos and Olympia Odos junction, to the south industrial area of Mandra.

On the other hand, there is a series of technical works that functioned adequately and extinguished further destruction.Indicatively, the following examples are illustrated:

1) The arrangement of the Soures stream with a twin open canal of rectangular concrete cross section, east of the Elefsina-Thiva National Road, in the industrial area, was generally sufficient 
2) The technical works at the river bed of Mikro Aikaterini north and east of the Magoula urban area was adequate, as well as its boxing in a closed rectangular section of concrete, upstream of Attiki Odos

3) The contribution of the arranged streams Sures and Small Catherine was sufficient (but marginally)

4) The diversion of the arranged streams Sures and Mikro Aikaterini, after their contribution, through a closed technical project of rectangular section of concrete and their discharge to Sarantapotamos was sufficient and expelled the flood of Elefsina.

\section{THE FLOOD IN WESTERN ATTICA - 1961}

The storm took place during the early hours of Monday 6 November 1961, between 02:00 and 08:00, reaching its peak at 04:00 to 06:00. The two-hour heavy rainfall was accompanied by intense hail. While characterizing the phenomenon, there was dispute between the Meteorological Service of the Hellenic Airport and the Meteorological Service of the Ministry of Aviation, with the first characterizing the storm as "a 5-hour storm of unusual severity" and the latter as a "cyclone". The severity of the storm can be comprehended by the fact that during the first 25 minutes, the Nea Philadelphia meteorological station recorded $31.00 \mathrm{~mm}$ of rain, with the rainfall having intensity $74.50 \mathrm{~mm} / \mathrm{hr}$.

The aforementioned storm caused Kifissos to flood for about $500 \mathrm{~m} 3 / \mathrm{s}$, which in itself would not be in position to bring about the incalculable losses that were eventually caused. Particular problems were observed along the river bed at the contribution of the stream of Liosia (common section of the stream of Eschatia and Michelis) at the height of the Bournazi - Ilion border, at the contribution of the stream Masha at the height of Peristeri, on the bridge of Nea Philadelphia (which collapsed in the area of Kokkinos Mylos), on the bridge of Piraeus Street, while also on the whole downstream section of the Piraeus bridge at the areas of Moschato and Faliro.

The epicenter of the disasters based on material losses but also on losses in human lives (40 in total) was in the periphery of Athens and more specifically in Bournazi and Ilion. Damages were also observed in the regions of Tzitzifies, Tavros, Egaleo, Peristeri, Agioi Anargyroi. There were 32 victims. In the region of Piraeus, problems arose at Keratsini, Kaminia, Drapetsona, Old Kokkinia, and Korydallos, Neo Faliro, Moschato, Agios Ioannis Rentis. There were 8 victims. According to newspapers of the time and the work of Floros and Vachaviolos (2009 and 2011), the storm and the subsequent flood, due to the time that it took place caught off guard not only the residents but also the civil protection services of Attica $[9,10]$. For several hours, areas in Bournazi, Ilion and Menidi were blocked by the amount of water, while the areas of Moschato and Tzitzifies up to the bay of Faliro, turned into a vast lagoon. The material damage was far from just in common networks benefits, since hundreds of houses collapsed and thousands more - as well shops - suffered structural damage. It is worth noting that major disasters, took place on a wide-ranging area beyond the main ones on Bournazi and Ilion.

\section{Cause of the storm}

The main cause of the disasters caused in Bournazi was the collapse of an elongated 5m-tall mound that had been manufactured by the Germans during the Occupation for the railway connection of the Anthoupoli mines to the line of the GSR (Greek State Railways). The embankment stretched throughout the length of today's Skamandrou Street and became the reason a river was created due to the flood runoffs and benefits of the upstream areas of Michelis and Eschatia. The waters overcame the construction that was eventually torn to a length of $150 \mathrm{~m}$. As a result, a great amount of water flowed towards the lower Bournazi area and literally drowned it, in particular the area between the streets of Skamandrou, Astrous and 
Konstantinoupoleos. The volume of water carried by the flood wave was estimated (Romaidis) at about $300,000 \mathrm{~m} 3$. The height of water in many of the streets of Bournazi reached nearly 2 meters.

The main cause of the disasters in the second area hit by the flood, Ilion, was the overflow of the Eshatia stream, which dragged along homes as well as human lives. The areas with the biggest casualties were the streets around the river and the Rimini district.

Following the tragic consequences of the flood in the above areas, the adjustment of the Eschatia stream in Flevas street as well as the Michelis stream was decided. The case of Kifisos was also revised, in order to be adjusted from its estuary until the area of Treis Gefyres.

In the field of civil protection, 5 hours after the beginning of the storm, the coordination of the situation was undertaken by the Higher Military Administration of Attica and the Islands (HMAAI), which put in place an Emergency Plan. The HMAAI was created as a tool for the coordination of the state and the military mechanism to address emergencies after the earthquake in the Ionian Islands in 1953, and had a satisfactory operation during the earthquakes of Karditsa (1954) and Volos (1955).

The forces mobilized were military with about 1,500 soldiers and motorized equipment, the Police, the Gendarmerie and the the Fire Brigade with 40 pumping units. Simultaneously, 20 help centers were set up in the affected areas, 15 in Athens and 5 in Piraeus. Direct priority jobs to tackle the flood, beyond helping the affected population were:

- Construction of the embankment of Skamandrou Street in Bournazi, using 25,000 sand bags

- Obstruction of the bridges of Piraeus and Agia Anna

- Evacuation of the lowlands of Moschato from the flood waters by cross-sectioning the surrounding avenues in order to reduce the discharge of the floods

- Restoration of the New Philadelphia bridge, which collapsed

During its passage, the storm and the resulting flood left behind many disasters. So, due to floods 40 human lives were lost in total. 32 in the Athens region and 8 in the region of Piraeus. In addition, many were left homeless, with the number reaching 4,500 people, 3,070 in the district of Athens, and 1,430 in the region of Piraeus. Regarding material damages, the collapsed houses were nearly 300, with the lion's share being in Ilion (100) followed by Egaleo (45), Peristeri (45) and Bournazi (45). Nearly 800 homes in the affected areas became uninhabited and taking into account buildings that have suffered less damage, all the buildings that faced problems were approximately 3.000.

\section{DIRECTIVES FOR FLOOD ADDRESSING AND PREVENTION}

Greece throughout its recent history, utilized two directives of the European Union. Directive 2000/60/EC (WFD) established a framework for Community action in the field of water policy, requiring integrated management plans to be developed for each river basin in order to achieve good ecological and chemical status by 2015 and it contributed in mitigating the effects of floods. However, reducing the risk of floods was not one of the principal objectives of WFD, nor did it take into account the future changes in the risk of flooding as a result of climate change. For that reason, the European Parliament and the Council of the European Union adopted the Directive 2007/60/EK aiming on the assessment and management of flood risks.

The implementation of Directive 2007/60 / EC aims to address and deal with problems that Greece is facing and that couldn't be tackled with the implementation of the Directive 2000/60 / EC, such as: 
- The insufficient administrative and technical infrastructure,

- The inadequate staffing and functioning of the competent authorities,

- The lack of sufficient quantitative, qualitative and other data (lack of logical and reliable recording and evaluation of natural and man-made materials water systems, lack of adequate hydrological, meteorological, hydrogeological and quality parameters, etc.),

- Country specifics (geomorphological structure, large spread coasts, small river basins, etc.)

The Commission checked how the Member States had transposed the Floods Directive. As of July 2018, the Commission had closed all infringement procedures related to the transposition; two cases remained open, however, for the late submission of the FRMPs by Greece and Spain. [European Court of Auditors, 2018] [11].

By comparing two floods that occurred very close to one another, but at quite a long time frame from one another we can evaluate how much the two directives were followed, which of the post-flood actions that were supposed to be taken were indeed taken and how this translates in casualties, both in human lives and properties.

\section{EDUCATION AND FLOOD RISK MANAGEMENT}

Education plays a lifesaving and life-sustaining role in an emergency situation and is essential to helping communities and learners rebuild their lives [Martone, 2007] [12]. Access to formal and non-formal education in the context of a natural disaster builds emotional and intellectual competences, mitigates the psychosocial impact by restoring a sense of normalcy and hope, provides physical protection, and conveys information about the risks of a natural disaster (INEE, 2010; IASC, 2006) [13,14].

In areas affected by a natural emergency, education fosters the development of children, youth, and adults, enabling them to better support long-term reconstruction activities and to build back a more prosperous society [IASC, 2006] [14]. Especially for all children to have access to a quality and safe education, sector-specific interventions are needed to augment the number and impact of educational activities supported through other sectors [USAID, 2014] [15].

Flood risk management aims to reduce the likelihood and/or the impact of floods. Experience has shown that the most effective approach is through the development of flood risk management programmes incorporating the following elements:

- Prevention: preventing damage caused by floods by avoiding construction of houses and industries in present and future flood-prone areas; by adapting future developments to the risk of flooding; and by promoting appropriate land-use, agricultural and forestry practices;

- Protection: taking measures, both structural and non-structural, to reduce the likelihood of floods and/or the impact of floods in a specific location;

- Preparedness: informing the population about flood risks and what to do in the event of a flood;

- Emergency response: developing emergency response plans in the case of a flood;

- Recovery and lessons learned: returning to normal conditions as soon as possible and mitigating both the social and economic impacts on the affected population [European Commission, 2004] [16].

\section{CONCLUSIONS}

As we can see from the data provided, the magnitude of loss, both social and economic, due to the floods, was in both cases (1961 and 2017) was great. According to newspaper data, the 
material damage caused by the flood of 1961 was the greatest of 50 years. However, even though there was a lack of organization and no European directive was supposed to be followed, there was an immediate plan of action with the Higher Military Administration of Attica and the Islands (HMAAI), creating an Emergency Plan. Many human lives were saved, and help was provided to those left homeless.

As far as infrastructure is concerned, actions were taken following the flood, while the lack of embankments and other structural measures that were needed was evident.

Regarding the educational part, Greek citizens were mostly unaware of how to handle a flooding situation, since there were no educational programs in schools or general information handed to the public in order to inform them of the actions that are needed to be taken before and after a flood has occurred.

The flood in Mandra in 2017 was of comparable magnitude as the one in 1961. The amount of victims was lower (23), as was the structural damages and the number of those left homeless. The army was not involved in the response mechanism, as it was in 1961, although other actors offered their help. Even though the statistics are in favor of the 2017 flood, it would be expected that with the implementation of 2 European Directives better measures would have been taken.

The insufficient administrative and technical infrastructure was evident and the communication between the competent authorities was weak. Moreover, the arbitrary human interventions within the river bed, the inadequacy of existing technical works (due to construction or non-cleaning / maintenance) or the complete absence of flood protection and drainage measures in some areas contributed to the increase of damages even more.

Back in 1961 the civil protection and the weather forecast mechanisms were almost unknown. The lack of inspection mechanisms was also evident, if we take look the main cause of the storm (the collapse of an elongated mound that was left untouched since 1943) so it is more expected that response would be a lot worse than that of 2017 . However, we can see that even in 2017, there was a lack of any central strategic planning and mitigating plans. Actors involved in the post-flood actions came face to face with bureaucratic issues and no type of awareness raising campaign was provided to the locals beforehand.

Therefore, issues that should immediately be tackled in Greece in order to have a fully functioning flood response mechanism and our proposals are:

a) The institutionalization of a national education policy on natural destructions and secondarily, a regional or local modification, according to the specificities of the area.

b) The reduction of the amount of bureaucracy and paperwork required for the communication between the actors responsible for the post-disaster actions

c) The immediate realization of the necessary projects and the undertaking of the measures needed to mitigate the flood risk (The municipality of Mandra has already started working on flood protection measures since August 2018, with plans of fully realizing the project until June 2019)

\section{References}

Hajat, S. et al., 2005. The Human Health Consequences of Flooding in Europe: a Review. In: Kirch, W., Bertollini, R., Menne, B. (Eds.), Extreme Weather Events and Public Health Responses. Springer Berlin Heidelberg, pp. 185-196

WHO, 2002. Floods: climate change and adaptation strategies for human health, WHO (World Health Organization - Regional office for Europe). 
Coates, L., 1999. Flood fatalities in Australia, 1788-1996. Aust. Geogr., 30(3): 391-408.

Mooney, L.E., 1983. Applications and implications of fatality statistics to the flash flood problems, Proceedings of the 5 th Conference on Hydrometeorology, Tulsa, USA.

Sörensen, J., \& Rana, A. (2013). Comparative Analysis of Flooding in Gothenburg, Sweden and Mumbai, India: A Review. Paper presented at International Conference on Urban Resilience.

Lekkas, E., Voulgaris, N., Lozios, S., (2017) Flash Flood in West Attica (Mandra, Nea Peramos) November 15, 2017, Newsletter of Environmental, Disaster and Crisis Management Strategies Issue no. 5.

Hellenic Republic, General Inspector of Public Administration, (2018), Audit report on the flooding of Mandra in 2017

Kontoes, C., et al., (2018) Analysis of the flood of 15/11/2017 in Western Attica using Satellite Telecommunication Operations.

Floros, I. (2009), “Database creation for the recording of flood events”, postgraduate thesis, ICSD Science and Water Resources Technology, National and Technical University of Athens (NTUA).

Vachaviolos, T, 2011. Methodology of identification vulnerable areas in floods in accordance with Directive 2007/60 (Bachelor's Thesis, Nation and Technical University of Athens).

European Union, European Court of Auditors, (2018), Floods Directive: progress in assessing risks, while planning and implementation need to improve, Special Report no. 25

Martone, G. (2007). Educating children in emergency settings: An unexpected lifeline

INEE and Inter-Agency Standing Committee (IASC), (2010), Education in emergencies training package. Geneva: Global Education Cluster

Inter-Agency Standing Committee (IASC), (2006), Protecting persons affected by natural disasters: IASC operational guidelines on human rights and natural disasters

USAID, (2014), Guide to Education in Natural Disasters: How USAID Supports Education in Crises

European Commission, (2004), Communication on Flood risk management; Flood prevention, protection and mitigation 